\title{
Tobacco control: prevention and cessation in Europe
}

\author{
Manfred Neuberger (D)
}

Received: 1 February 2019 / Accepted: 12 March 2019 / Published online: 2 April 2019

(C) The Author(s) 2019

\begin{abstract}
Summary Reasons for high smoking prevalence in Europe compared to Australia and North America are low prices of tobacco adjusted for purchasing power and poor smoke-free legislation and enforcement in Central and Eastern Europe. High rates of passive smoking in Czechia, Slovakia, Poland and Austria are associated with weak implementation of smoke-free public rooms, especially in the hospitality industry. In 2018 Austria cancelled the smoking ban in all bars and restaurants and continued to allow access to minors, while Hungary since 2012 showed remarkable success by limiting supply of cigarettes and by banning access of minors to tobacco shops. Even more advanced are Western European countries because of lower affordability of cigarettes, ban of smoking rooms and tobacco advertising, plain packaging and public information campaigns. Smoking cessation services across Europe make use of quitlines, provide internet counseling and apps for self-help. Cooperation with physicians should be improved and could help oncologists to combine cancer screening with smoking cessation. Cancer therapy is more successful after smoking cessation.
\end{abstract}

Keywords Tobacco control - Smoking prevention . Smoking cessation $\cdot$ Europe $\cdot$ Cancer prevention

\section{Progress in tobacco control}

Smoking prevalence in Australian adults ( $\geq 18$ years) went down from $28 \%$ (1990) to $15 \%$ (2017) and in adolescents (15-17 years) to $3 \%[1,2]$ by legislative and fiscal measures listed in Table 1. Similar suc-

Prof. M. Neuberger (ه)

Center of Public Health, Medical University of Vienna,

Felbigergasse 3/2/18, 1140 Wien, Austria

manfred.neuberger@meduniwien.ac.at cess in tobacco control was seen in North America. In the United States cigarette smoking prevalence in adults ( $\geq 18$ years) declined from $28 \%$ (1990) to $14 \%$ (2017) and the use of any tobacco product (including e-cigarettes, heated tobacco and oral tobacco) to $19 \%$. In the age group 18-24 years cigarette use went down to $10 \%$ and of any tobacco product to $18 \%$ [3].

Newly industrializing countries like Brazil or India also succeeded in reducing their smoking prevalence, and in many developing countries smoking rates among women are still low. In China only $3 \%$ of women are smokers, but most of these passive smokers and their lung cancer risk is determined by second-hand smoke (SHS) and other indoor pollution (cooking, heating, occupational) and ambient air pollution (fine particles from traffic, coal power plants and other industrial polluters). In China there is an urgent need for smoking cessation among men $(68 \%$ smokers) and of smoking prevention for women, including passive smoking [4]. Worldwide the smoking epidemic has not yet reached full maturity in women [5] and also in several European countries smoking prevalence in females is still on the rise.

\section{High smoking prevalence in Europe}

Fig. 1 shows the daily smoking prevalence in percent of the population aged $\geq 15$ years, according to the Organisation for Economic Co-operation and Development (OECD) [6]. The bars show the smoking rates for 2015 and the figures below the rates for 2017 or latest available in European countries [7]. For comparison the smoking rates including occasional smoking are given above the bars for highlighted European Union (EU) members in Central Europe, according to the Eurobarometer survey [8, 9]. Greece, Hungary and Latvia had a high smoking prevalence, but recently showed a large decline. According to the OECD 44 states have 
Table 1 Legislation and taxation associated with a continuous decrease in smoking prevalence in Australia

\begin{tabular}{|l|l|}
\hline 1991 & Tobacco advertising ban in print media \\
\hline 1992 & Increase of tobacco excise tax \\
\hline 1993 & Tobacco advertising prohibition act \\
\hline $1994-2003$ & Smoke-free legislation (schools, workplaces, public rooms) \\
\hline 1995 & Health warnings on cigarette packs \\
\hline 1997 & National tobacco campaign \\
\hline $1998-2006$ & Advertising bans at point of sale \\
\hline 2001 & Smoke-free restaurants \\
\hline 2003 & Hospitality industry completely smoke-free \\
\hline 2006 & Graphic health warnings on packs \\
\hline $2007-2012$ & Smoking bans in private cars carrying children \\
\hline 2009 & Tackling indigenous smoking initiative \\
\hline 2010 & 25\% rise of tobacco excise tax \\
\hline 2012 & Point of sale display bans, larger warnings + plain packaging \\
\hline $2013-2020$ & 12.5\% rise of tobacco excise tax on Sept. 1st of each year (to push prize to $\$ 40 /$ pack) \\
\hline $2015-17$ & Ban of sale, possession and use of nicotine in the form of electronic cigarettes \\
\hline
\end{tabular}

reduced smoking since 2000, with the exception of Austria, Slovakia and Indonesia [6]. The fall in smoking rates, however, was much less pronounced in Europe than in Australia and North America. Pioneers like Iceland, Sweden and Norway reached rates like Utah and California, but on average smoking prevalence had been reduced by 2015 to only $26 \%$ of the EU population aged $\geq 15$ years, while it reduced to $15 \%$ of the US population aged $\geq 18$ years. This large difference cannot be explained by fewer efforts in tobacco dependence treatment, since most EU members provide a national quitline and additional smoking cessation services free of charge. The main reasons for Europe lagging behind North America and Australia include low prices of tobacco and poor smoke-free legislation and enforcement in Eastern and Central Europe [10].

\section{Key elements of tobacco control}

Both the World Bank [11, 12] and the World Health Organisation (WHO) $[13,14]$ recommended raising tobacco taxes to around $80 \%$ of the retail price. In Europe cigarette consumption decreased by $5 \%-7 \%$ for a $10 \%$ increase in the real price [15]. This decrease was most pronounced in adolescents, individuals with low socioeconomic status and individuals with low education that are difficult to reach with health campaigns $[14,15]$. Tobacco prices in Europe show a decline from Northwest to Southeast. Compared to the EU average $(100 \%)$ the tobacco prices reach $223 \%$ in Norway, $208 \%$ in Ireland, $202 \%$ in Iceland and $194 \%$ in the United Kingdom, but only 35\% in Albania, $40 \%-41 \%$ in Bosnia, Serbia and Kosovo and 51\% in Bulgaria [16]. However, affordability is more important than the raw price. Fig. 2 gives the raw prices of 20 cigarettes in Central Europe and prices adjusted for purchasing power, showing the highest affordability of a pack of cigarettes in the Czech Republic, followed by Switzer- land, Slovenia and Austria. Countries with a decline in cigarette affordability from 2008 to 2016 are graphed in a recent WHO report on the monitoring of tobacco use and prevention policies [17]. In Europe only Norway, Ireland, Iceland and United Kingdom reached acceptably levels to date.

The second most important tobacco control measure is to protect people from tobacco smoke by smoke-free legislation for workplaces and public places and its enforcement $[10,11,13,17-19]$. Smokefree rooms are a prerequisite to denormalizing smoking, so that tobacco smoke is recognized as air pollution, its social acceptance decreases, and it becomes a motivation for smokers to reduce or quit. Also the seduction of adolescents is hindered by smoke-free public rooms (without exceptions for the hospitality industry). Poor compliance with the Framework Convention on Tobacco Control [20], relatively high affordability and availability of cigarettes and poor protection of unborn, adolescents and other nonsmokers were the main reasons why Austria has achieved the lowest score since 2007 on the European Tobacco Control Scale [10, 21-23]. Against the wish of $70 \%$ of the population Austria's new government cancelled the smoke-free hospitality legislation in 2018 [19].

\section{Problems and solutions in Europe}

In Central Europe Austria has a higher smoking prevalence than its neighbors and, with the exception of Germany, all smoking rates for EU members in Central Europe exceeded the EU average [24]. Also, passive smoking in percent of the population aged $\geq 15$ years was above the EU average in the Czech Republic, Poland, the Slovak Republic and Austria, but has decreased considerably in Hungary since the reform of tobacco legislation in 2012 (Table 2). In the Tobacco Control Scale a country can gain up to 30 points for 
Fig. 1 Smoking prevalence, Eurobarometer 2015, $2017[8,9]$ and OECD 2016, 2018 [7]

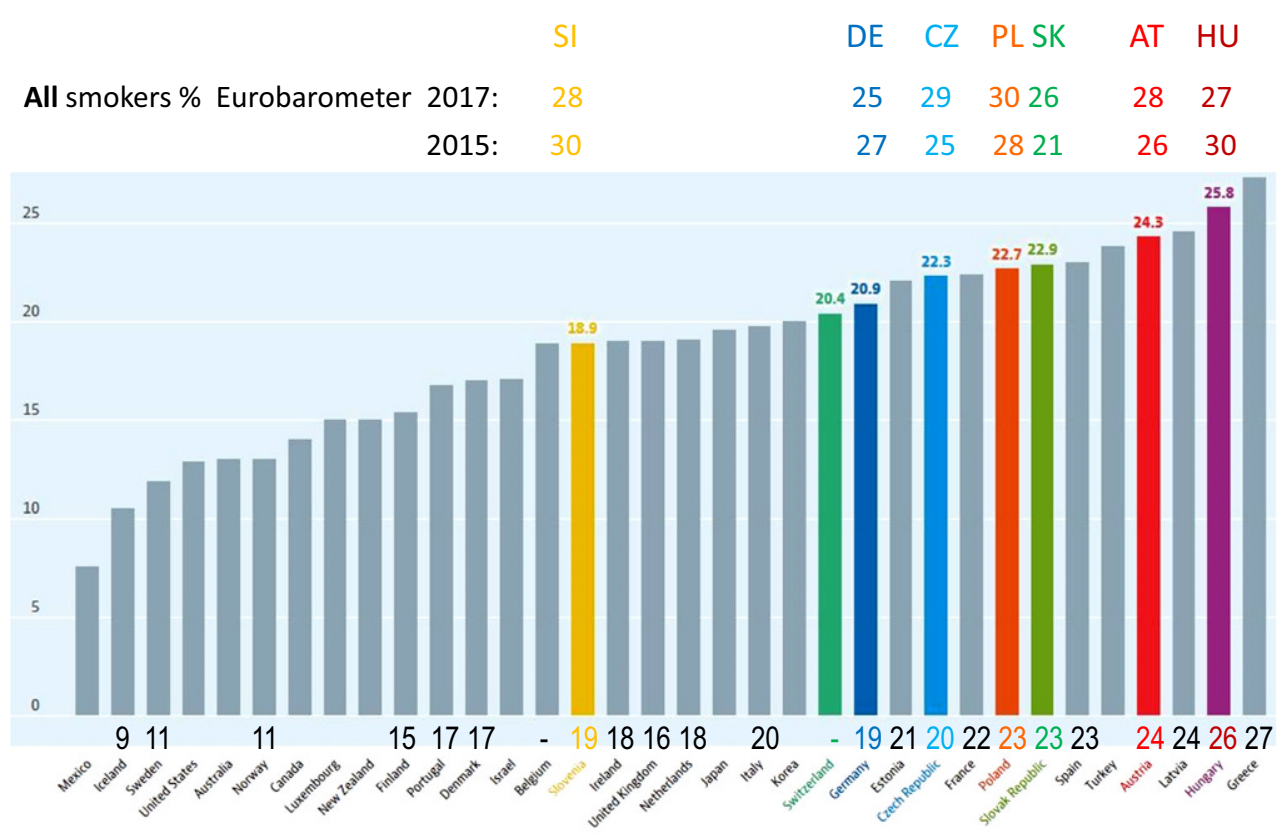

Fig. 2 Price of 20 cigarettes, Eurostat 2015, 2016 [16]

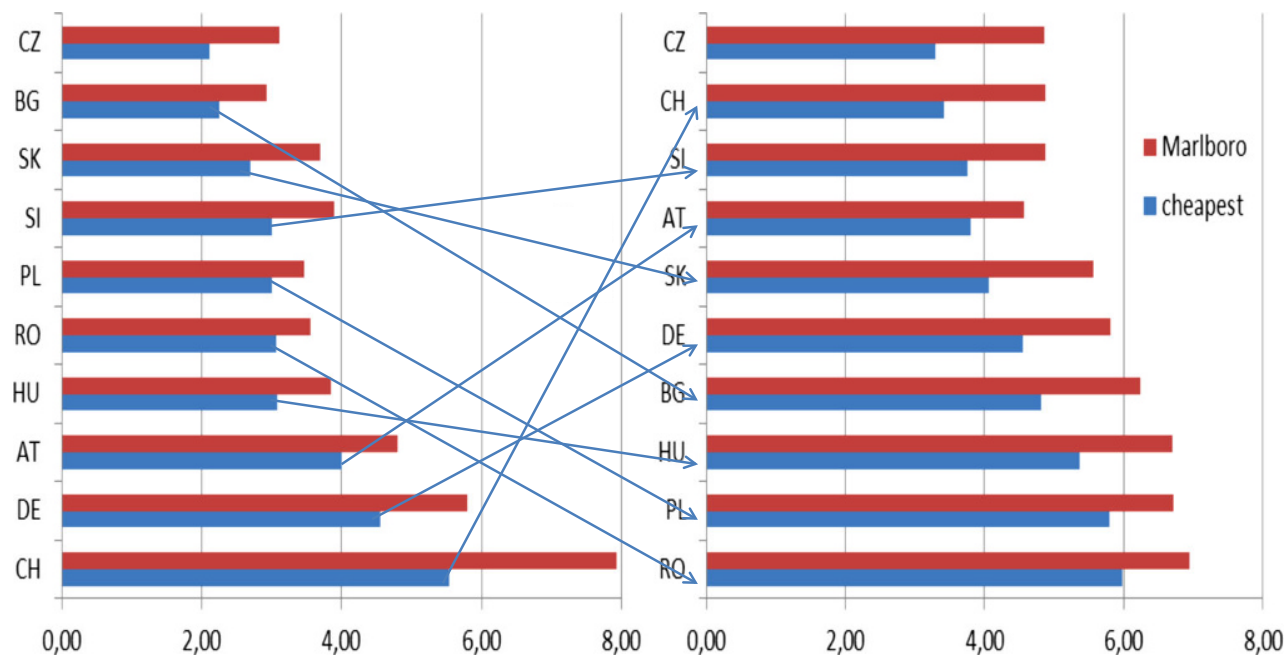

a high tobacco price adjusted for purchasing power, up to 22 points for smoke-free legislation and enforcement, up to 15 points for public information and campaigning and up to 13 points for comprehensive bans on tobacco advertising, promotion and sponsoring.

It is insufficient to look at the spending on information on the benefits of non-smoking, if these campaigns are not evaluated, address children only or serve mainly to distribute a photo of the health minister for his reputation as a health campaigner. Hypocritical politicians prefer to talk about "improvement of youth protection", but still give minors access to tobacco shops and smoking rooms, refuse to ban tobacco advertising and block independent mystery shopping for age control. They know that the elec- tronic age control by vending machines has failed, but they keep them due to business interests. Hungary previously had extremely high smoking rates and lung cancer rates, but shortened cigarette supply by a radical reduction of retail stores and banned access of minors to tobacco shops in 2012. Hungary has no cigarette vending machines and banned any outdoor tobacco advertising [25].

Comprehensive bans on tobacco advertising, promotion and sponsoring are lacking in many European countries and implementation of the EU tobacco product directive is incomplete [26]. Larger picture warnings have been introduced, but to date plain packaging is obligatory only in France, the United Kingdom and Ireland. This removal of trademarks, logos, colors and graphics, apart from the government 
Table 2 Active and passive smoking in the EU-28 and Central EU

\begin{tabular}{|c|c|c|c|c|c|c|}
\hline & \multicolumn{3}{|c|}{$\%$ Current smokers } & \multicolumn{3}{|c|}{$\%$ Passive smokers } \\
\hline & Daily & Occasionally & Total & $<1 \mathrm{~h}$ & $\geq 1 \mathrm{~h}$ & Total \\
\hline EU-28 & 19.2 & 4.7 & 24.0 & 10.7 & 10.9 & 21.6 \\
\hline Germany & 15.9 & 5.8 & 21.7 & 9.2 & 7.7 & 16.9 \\
\hline Slovenia & 18.9 & 5.4 & 24.2 & 9.9 & 6.2 & 16.2 \\
\hline Poland & 22.7 & 3.4 & 26.1 & 15.0 & 14.5 & 29.5 \\
\hline Hungary & 25.8 & 1.7 & 27.5 & 3.1 & 6.8 & 9.9 \\
\hline Czechia & 21.5 & 7.1 & 28.7 & 19.0 & 11.0 & 30.1 \\
\hline Slovakia & 22.9 & 6.7 & 29.5 & 17.5 & 11.7 & 29.2 \\
\hline Austria & 24.3 & 5.7 & 30.0 & 13.5 & 14.8 & 28.5 \\
\hline
\end{tabular}

health warning, and brand names presented in a standardized typeface, was first introduced in Australia. In Norway, Hungary and Slovenia laws were passed to make plain packaging obligatory and similar laws are prepared at present in Romania and other EU countries, so that they will get closer to the maximum of 10 points, which is given in the Tobacco Control Scale for appropriate warnings.

\section{Smoking cessation services}

Broad population measures such as taxes and smokefree areas are more effective than individual treatment services. Therefore, only a maximum of 10 points can be achieved in the Tobacco Control Scale for helping smokers to stop smoking and stay abstinent. This requires recording of smoking status in medical notes, brief advice in primary care, incentives for documentation and reimbursement of family doctors for providing advice. Most EU members have national quitlines covering all regions of the country, and many answer the phone at least $30 \mathrm{~h}$ a week and record messages outside of these office hours to answer them later. Some provide internet counseling and offer physicians the possibility to recommend a patient by fax, so that they can be called back by the quitline with support in their efforts. Apps for self-help are also in use, especially for younger smokers. A free quitline, combined with a free cessation support network, including services in the most prevalent foreign languages, is the optimal model [13, 14]. Switzerland finances tobacco prevention and cessation (including training of cessation experts) by a levy on the tobacco tax and provides reimbursement for counselling and pharmaceutical aids. High success rates have been reported from group therapy and motivation seminars in the workplace [27-29]. The European Network on Smoking Prevention has published guidelines for treating tobacco dependence [30], including behavioral counselling with pharmaceutical support by varenicline, cytisine, bupropion, clonidine, nortryptiline, nicotine replacement or combinations. Electronic cigarettes cannot be recommended, since their content is not controlled in the same way as pharmaceutical products and there are concerns that the tobacco industry uses them as a gateway to nicotine addiction rather than as a cessation aid [30]. No pharmaceutical should be given without counselling. Special recommendations are given for the treatment of smoking risk groups (adolescents, pregnant women, smokers with postcessation weight gain and patients with respiratory, cardiovascular or psychiatric diseases, cancer and other comorbidities) [30].

\section{Relevance for oncology}

Smoking is the major cause of cancer. Any form of tobacco can cause cancer. Oncologists see the benefits of quitting smoking in their patients later than cardiologists, nevertheless they should be aware that their therapy is more successful after smoking cessation [31-35]. The earlier the patient can be convinced to stop smoking and using nicotine, the better his prognosis. Lung cancer screening needs to be combined with a smoking cessation program. Incidence of cancer (and other diseases caused by tobacco and promoted by nicotine) can only be reduced by tobacco prevention, focusing on young people and including SHS. The most important instrument for tobacco control is the Framework Convention for Tobacco Control [20]. Article 5.3 explains why the battle against the tobacco epidemic cannot be won with but only against the tobacco industry.

Funding Open access funding provided by Medical University of Vienna.

Conflict of interest M. Neuberger declares that he has no competing interests.

Open Access This article is distributed under the terms of the Creative Commons Attribution 4.0 International License (http://creativecommons.org/licenses/by/4.0/), which permits unrestricted use, distribution, and reproduction in any medium, provided you give appropriate credit to the original author(s) and the source, provide a link to the Creative Commons license, and indicate if changes were made. 


\section{References}

1. Department of Health. Smoking prevalence rates. 2018. http://www.health.gov.au/internet/publications/ publishing.nsf/Content/tobacco-control-toc $\sim$ smokingrates..

2. Australian Bureau of Statistics. National health survey: First results, 2017-18. 2018. https://www.abs.gov. au/ausstats/abs@.nsf/Lookup/by\%20Subject/4364.0.55. 001 2017-18 Main\%20Features Smoking 85. .

3. Wang TW, Asman K, Gentzke AS, et al. Tobacco product use among adults-United States, 2017. 2018. https://www. cdc.gov/mmwr/volumes/67/wr/mm6744a2.htm.

4. Chen Z, Peto R, Zhou M, et al. Contrasting male and female trends in tobacco-attributed mortality in China: Evidence from successive nationwide prospective cohort studies. Lancet. 2015;386:1447-56.

5. O'Keeffe LM, Taylor G, Huxley RR, et al. Smoking as a risk factor for lung cancer in women and men: A systematic review and meta-analysis. 2018. https://www.ncbi.nlm. nih.gov/pmc/articles/PMC6194454/..

6. OrganisationforEconomicCooperation andDevelopment. Tobacco and alcohol consumption. 2016. https://www. oecd-ilibrary.org/sites/soc_glance-2016-25-en/index. html?itemId=/content/component/soc_glance-2016-25en..

7. OrganisationforEconomic CooperationandDevelopment. OECD data. Daily smokers. 2017. https://data.oecd.org/ healthrisk/daily-smokers.htm..

8. European Commission. EC special Eurobarometer 429. 2015. http://ec.europa.eu/commfrontoffice/ publicopinion/index.cfm/ResultDoc/download/ DocumentKy/65707..

9. European Commission. EC special Eurobarometer 458. 2017. http://ec.europa.eu/COMMFrontOffice/ PublicOpinion..

10. Joossens L, Raw M. The tobacco control scale 2016 in Europe. 2017. https://www.tobaccocontrolscale. org/wp-content/uploads/2017/03/TCS-2016-in-EuropeCOMPLETE-LoRes.pdf..

11. World Bank. Tobacco control at a glance. 2003. http:// siteresources.worldbank.org/INTPH/Resources/3760861238076532997/TobaccoControl2010Nov15.pdf..

12. World Bank. Tobacco tax reform at the crossroads of health and development. 2017. http://documents.worldbank org/curated/en/491661505803109617/Main-report..

13. World Health Organization. MPOWER. 2008. https://www. who.int/tobacco/mpower/mpower_report_six_policies_ 2008.pdf.

14. World Health Organization. Making tobacco a thing of the past. 2015. http://www.euro.who.int/en/ health-topics/disease-prevention/tobacco/publications/ 2015/making-tobacco-a-thing-of-the-past-roadmapof-actions-to-strengthen-implementation-of-the-whoframework-convention-on-tobacco-control-in-theeuropean-region-2015-2025-2015.

15. Gallus S, Schiaffino A, La Vecchia C, et al. Price and cigarette consumption in Europe. Tob Control. 2006;15(2):114-9.

16. Eurostat. Comparative price levels for food, beverages and tobacco. 2018. https://ec.europa.eu/ eurostat/statistics-explained/index.php/Comparative price_levels_for_food,_beverages_and_tobacco\#Price levels_for_food.2C_beverages_and_tobacco..

17. World Health Organization. WHO report on the global tobacco epidemic 2017. 2017. http:/ / www.who.int/tobacco/ global_report/2017/en.
18. Neuberger M. Failure of tobacco control in central europe. 2013. https://www.aerzteinitiative.at/OccMedHlthAff13. pdf..

19. Hefler M. Austria: New government a tobacco industry victory? 2018. http://blogs.bmj.com/tc/2018/01/09/ austrias-new-government-a-victory-for-the-tobaccoindustry-and-public-health-disaster/..

20. World Health Organization. Framework convention on tobacco control. 2003. https://www.who.int/fctc/en/..

21. HorakF, Fazekas T, ZacharasiewiczA, et al. The fetal tobacco syndrome. Wien KlinWochenschr. 2012;124(5-6):129-45. A statement of the Austrian Societies for General- and Family Medicine (OGAM), Gynecology and Obstetrics (OGGG), Hygiene, Microbiology and Preventive Medicine(OGHMP), Pediatrics and Adolescence Medicine (OGKJ) as well as Pneumology (OGP).

22. MoshammerH,HoekG, Luttmann-Gibson H, etal. Parental smoking and lung function in children. An international study. Am J Respir Crit Care Med. 2006;173:1255-63.

23. Muttarak R, Steiber N, Gallus S. Smoking ban in Austria: A long overdue step but still a lot to be done. Lancet. 2015;385(9972):941-2.

24. Eurostat. News release 245. 2016. https://ec.europa.eu/ eurostat/documents/2995521/7762296/3-07122016-APEN.pdf/..

25. Laki M. Restructuring and re-regulation of the Hungarian tobacco market. 2015. http://cjssp.uni-corvinus.hu/ index.php/cjssp/article/download/142/pdf..

26. European Commission. Tobacco product directive. 2014. https://eur-lex.europa.eu/legal-content/EN/TXT/PDF/? uri=CELEX:32014L0040\&from $=$ EN..

27. Hutter HP, Moshammer H, Neuberger M. Smoking cessation at the workplace: One year success of short seminars. Int Arch Occup Environ Health. 2006;79:42-8.

28. Moshammer H, Neuberger M. Long term success of short smoking cessation seminars supported by occupational health care. AddictBehav. 2007;32(7):1486-93.

29. Keogan S, Li S, Clancy L. Allen Carr's Easyway to stop smoking-A randomised clinical trial. 2018 . https://tobaccocontrol.bmj.com/content/early/2018/10/ 25/tobaccocontrol-2018-054243.info..

30. European Network for Smoking and Tobacco Prevention. Guidelines for treating tobacco dependence. 2017. http:// elearning-ensp.eu/mod/page/view.php?id=36. .

31. Tao L, Wang R, Gao YT, Yuan JM. Impact of postdiagnosis smoking on long-term survival of cancer patients: The Shanghai cohort study. Cancer Epidemiol Biomarkers Prev. 2013;22(12):2404-11.

32. Parsons A, Daley A, Begh R, Aveyard P. Influence of smoking cessation after diagnosis of early stage lung cancer on prognosis: Systematic review of observational studies with meta-analysis. BMJ. 2010;340:b5569. https://doi.org/10. 1136/bmj.b5569.

33. Dobson Amato KA, Hyland A, Reed R. Tobacco cessation May improve lung cancer patient survival. J Thorac Oncol. 2015;10(7):1014-9.

34. Taylor C, Correa C, Duane FK. Estimating the risks of breast cancer radiotherapy: Evidence from modern radiation doses to the lungs and heart and from previous randomized trials. J Clin Oncol. 2017;35(15):1641-9. https://doi.org/10. 1200/jco.2016.72.0722.

35. Padron-Monedero A, Tannenbaum SL, Koru-Sengul T, et al. Smoking and survival in female breast cancer patients. Breast Cancer Res Treat. 2015;150(2):395-403. https://doi. org/10.1007/s10549-015-3317-3. 
Publisher's Note Springer Nature remains neutral with regard to jurisdictional claims in published maps and institutional affiliations.

- For latest news from international oncology congresses see: http://www.springermedizin.at/ memo-inoncology 